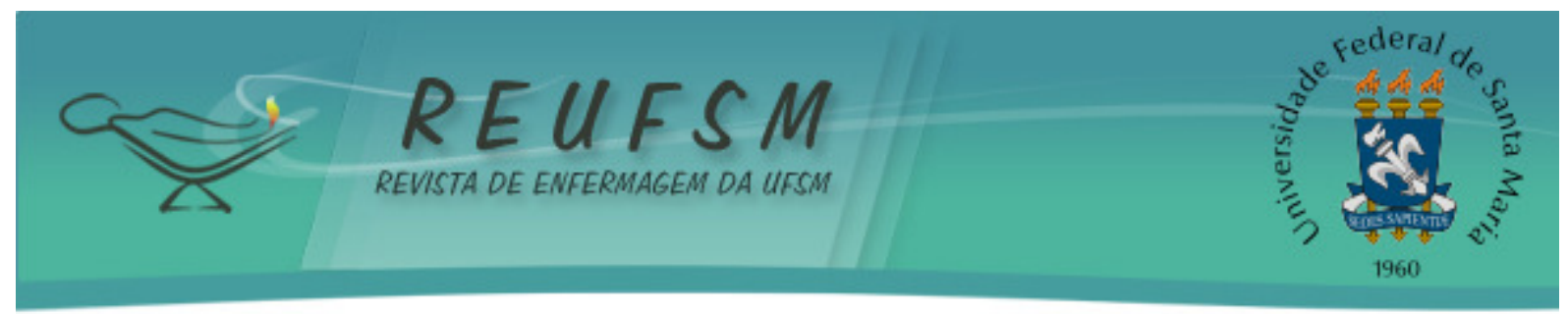

ARTIGO ORIGINAL

\title{
GESTÃO DA QUALIDADE NA ASSISTÊNCIA DE ENFERMAGEM EM UNIDADES DE CLÍNICA CIRÚRGICA
}

\author{
QUALITY MANAGEMENT IN NURSING ASSISTANCE AT CLINICAL SURGERY UNIT \\ GESTIÓN DE LA CALIDAD EN ASISTENCIA DE ENFERMERÍA EN UNIDADES DE CLÍNICA \\ QUIRÚRGICA
}

\author{
Liange Arrua Rabenschlag ${ }^{1}$ \\ Suzinara Beatriz Soares de Lima ${ }^{2}$ \\ Thaís Dresch Eberhardt ${ }^{3}$ \\ Marciane Kessler ${ }^{4}$ \\ Rhea Silvia de Avila Soares ${ }^{5}$ \\ Silviamar Camponogara ${ }^{6}$
}

Doi: $10.5902 / 2179769215891$

RESUMO: Objetivo: identificar as facilidades e dificuldades encontradas na gestão da qualidade da assistência de enfermagem em unidade de clínica cirúrgica. Método: pesquisa descritiva, qualitativa, realizada num hospital universitário da Região Sul do Brasil, de julho a setembro de 2013. Foram realizadas entrevistas semiestruturadas avaliadas por meio de análise temática de Minayo. Resultados: emergiram duas categorias: facilidades da gestão na qualidade em unidade de clínica cirúrgica, constituída a partir dos temas experiência profissional, interação com a equipe e integração com o ambiente de trabalho; e dificuldades da gestão na qualidade em unidade de clínica cirúrgica, através dos temas que direcionaram para a sobrecarga de trabalho, o número insuficiente de profissionais de enfermagem, estrutura física e insuficiência de recursos materiais. Conclusão: o estudo poderá contribuir com os enfermeiros, pois identifica fatores facilitadores e dificultadores na gestão da qualidade da assistência de enfermagem, possibilitando estratégias na busca de um cuidado efetivo e de excelência na saúde.

Descritores: Enfermagem; Gestão de qualidade; Cuidados de enfermagem; Enfermagem perioperatória; Pesquisa qualitativa.

ABSTRACT: Aim: to identify the facilities and difficulties that nurses encounter in management of quality in nursing assistance at clinical surgery unit. Method: descriptive and qualitative research performed at a University Hospital in South Brazil, from July to September 2013. Semi-structured interviews were conducted and evaluated according to Minayo thematic analysis. Results: two thematic categories were emerged: facilities in quality management at clinical surgery unit, composed by the topics professional

\footnotetext{
${ }^{1}$ Enfermeira, Mestre em Enfermagem, Auxiliar em saúde no Hospital Universitário de Santa Maria, Santa Maria, Rio Grande do Sul, Brasil. E-mail: licaufsm@hotmail.com.

2 Enfermeira, Doutora em Enfermagem, Professora Adjunta da Universidade Federal de Santa Maria, Santa Maria, Rio Grande do Sul, Brasil. E-mail: suzibslima@yahoo.com.br.

${ }^{3}$ Enfermeira, Especialista em Gerenciamento de Enfermagem em Clínica Médica e Cirúrgica, Mestranda em Enfermagem, Bolsista Demanda Social CAPES, Universidade Federal de Santa Maria, Santa Maria, Rio Grande do Sul, Brasil. E-mail: thaiseberhardt@gmail.com.

${ }^{4}$ Enfermeira, Mestranda em Enfermagem, Bolsista FAPERGS, Universidade Federal de Santa Maria, Santa Maria, Rio Grande do Sul, Brasil. E-mail: marciane.kessler@hotmail.com.

${ }^{5}$ Enfermeira, Mestre em Enfermagem, Doutoranda em Enfermagem, Universidade Federal de Santa Maria, Santa Maria, Rio Grande do Sul, Brasil. E-mail: rheasilviasoares@yahoo.com.br.

${ }^{6}$ Enfermeira, Doutora em Enfermagem, Professora Adjunta da Universidade Federal de Santa Maria, Santa Maria, Rio Grande do Sul, Brasil. E-mail: silviaufsm@yahoo.com.br.
} 


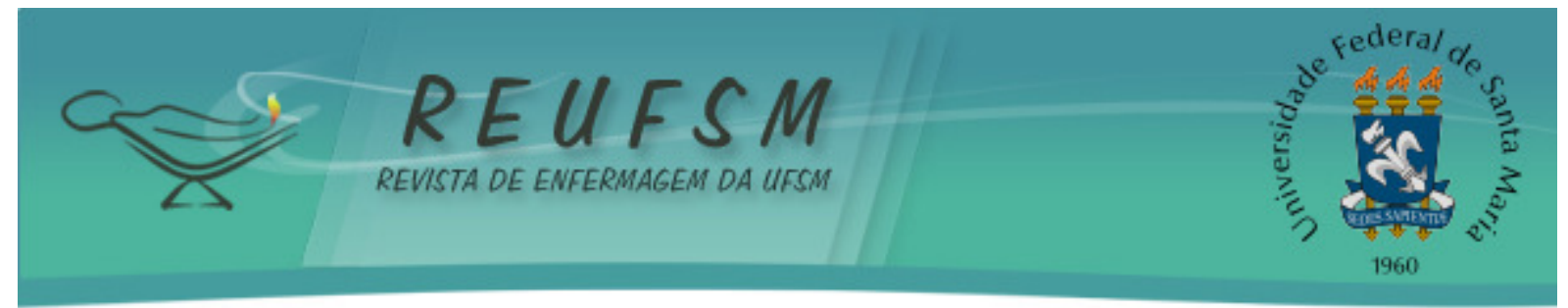

experience, interaction with teamwork and integration with the workplace; and difficulties in quality management at clinical surgery unit through themes that pointed to work overload, the insufficient number of nursing staff, physical structure and insufficiency of material resources. Conclusion: the study will contribute with the nurses, because identifies facilitating and hindering factors in management of quality in nursing assistance, enabling strategies in search for effective care and health excellence.

Descriptors: Nursing; Quality management; Nursing care; Perioperative nursing; Qualitative research.

RESUMEN: Objetivo: reconocer facilidades y dificultades encontradas en la gestión de calidad de asistencia de enfermería en unidad de clínica quirúrgica. Método: investigación descriptiva, cualitativa, realizada en hospital universitario de la Región Sur de Brasil, entre julio y septiembre de 2013. Se realizaron entrevistas semi-estructuradas evaluadas mediante análisis temático de Minayo. Resultados: surgieron dos categorías: facilidades de gestión de la calidad en unidad de clínica quirúrgica, formada a partir de los temas experiencia profesional, interacción con el equipo y integración con el ambiente de trabajo; y dificultades de la gestión de calidad en unidad clínica quirúrgica, por medio de temas que apuntan a la sobrecarga de trabajo, el número insuficiente de profesionales de enfermería, estructura física y insuficiencia de recursos materiales. Conclusión: el estudio contribuirá con los enfermeros, pues identifica factores facilitadores y dificultadores en la gestión de calidad de asistencia de enfermería, permitiendo estrategias en la búsqueda de atención efectiva y excelencia en salud.

Descriptores: Enfermería; Gestión de calidad; Atención de enfermería; Enfermería perioperatoria; Investigación cualitativa.

\section{INTRODUÇÃO}

A gestão da qualidade em saúde representa importante parcela no processo de melhoria das instituições, pois direciona as ações na busca da excelência do cuidado, por meio de práticas centralizadas nas demandas dos pacientes. ${ }^{1}$ Assim, utilizou-se, para este estudo, o referencial teórico de qualidade de Avedis Donabedian, considerando-se os elementos de estrutura, processo e resultado, ${ }^{2}$ além dos sete pilares da qualidade ${ }^{3}$.

A estrutura contempla características relativamente estáveis das instituicõoes área física, recursos humanos, materiais, financeiros e modelo organizacional. 0 processo refere-se ao conjunto de atividades desenvolvidas, nas relações estabelecidas entre os profissionais e os pacientes. 0 resultado é a obtenção das características desejáveis dos produtos ou serviços, retratando os efeitos da assistência à saúde. ${ }^{2}$ Já os sete pilares da qualidade são: eficácia, efetividade, eficiência, otimização, aceitabilidade, legitimidade e equidade. ${ }^{3}$

A enfermagem, então, como parte integrante dos serviços de saúde, vivencia essa preocupação com a qualidade, procurando inserir-se na busca da qualidade da gestão, repercutindo em amadurecimento da sua prática. ${ }^{4}$

Ao reportar-se às unidades cirúrgicas, percebe-se a necessidade de cuidados específicos durante o período perioperatório e, em especial, dos cuidados da enfermagem. ${ }^{5}$ Assim, para a excelência na qualidade da assistência prestada ao paciente cirúrgico, torna-se fundamental o planejamento das ações assistenciais da enfermagem.

0 presente estudo justifica-se pela importância que o evento cirúrgico representa para o indivíduo, bem como a relevância da gestão do cuidado como estratégia para a efetivação de uma assistência hospitalar de qualidade. Dessa forma, partiu-se da seguinte 


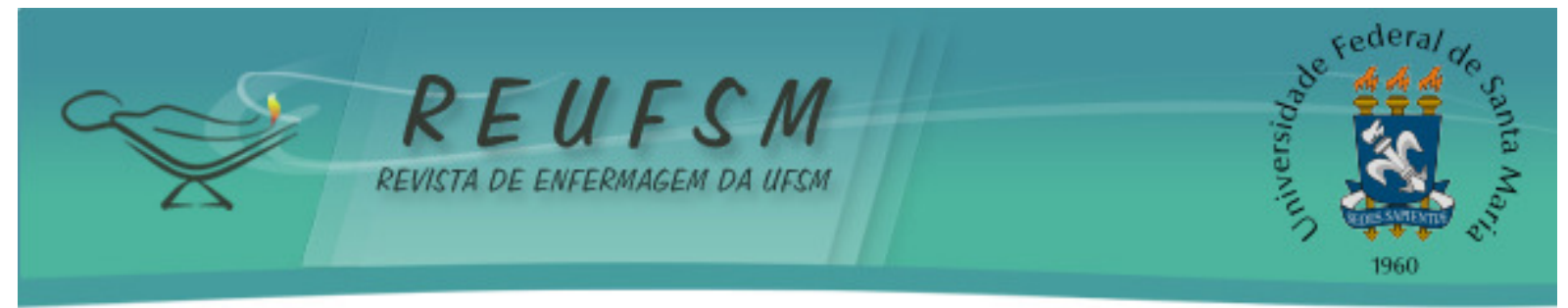

questão de pesquisa: Quais as facilidades e dificuldades encontradas pelos enfermeiros na gestão da qualidade da assistência de enfermagem na unidade de clínica cirúrgica?

Este estudo poderá contribuir com novas investigações que abordem aspectos relativos à gestão da qualidade na assistência em unidade de clínica cirúrgica, tendo em vista ser uma temática fundamental para o desenvolvimento de um trabalho com qualidade. Sendo assim, esta pesquisa teve como objetivo identificar as facilidades e dificuldades encontradas na gestão da qualidade da assistência de enfermagem em unidade de clínica cirúrgica.

\section{MÉTODO}

Trata-se de uma pesquisa qualitativa, de natureza exploratório-descritiva. 0 cenário de coleta de dados foi uma unidade de clínica cirúrgica de um hospital universitário, localizado na Região Sul do Brasil. Este hospital caracteriza-se como de nível terciário de alta complexidade e é referência em saúde para a região central do Estado do Rio Grande do Sul. A referida instituição atua como hospital-escola, com sua atenção voltada para o desenvolvimento do ensino, pesquisa, extensão e assistência em saúde. ${ }^{6}$

Participaram da pesquisa 10 enfermeiros. Os critérios de inclusão utilizados para seleção dos participantes do estudo foram: ser servidor estatutário, atuante há mais de seis meses no setor. Como critério de exclusão foram considerados: aqueles que estivessem em período de férias, licença-prêmio, saúde ou maternidade no período previsto de coleta dos dados. Não houve exclusões, logo, os participantes da pesquisa foram todos os enfermeiros lotados na referida unidade.

A coleta de dados se realizou entre os meses de julho e setembro de 2013, mediante entrevista semiestruturada gravada em sistema digital. A entrevista seguiu um roteiro com questões direcionadas aos objetivos da pesquisa: Fale-me sobre seu processo de trabalho relacionando à gestão da qualidade da assistência de enfermagem. Identifica facilidades na gestão da qualidade da assistência? Identifica dificuldades na gestão da qualidade da assistência? Para preservar o anonimato, os entrevistados foram identificados pela letra $E$ de enfermeiro, seguida de número ordinal na sequência das entrevistas ( $E 1$, E2, E3...).

Os dados foram analisados por meio de análise temática de Minayo, onde o tema está ligado a uma afirmação a respeito de determinado assunto, que comporta um feixe de relações e pode ser graficamente representado por meio de palavras, frases ou de um resumo. A análise temática desdobra-se basicamente em três etapas: Pré-Análise; Exploração do material; Tratamento dos resultados obtidos e Interpretação. ${ }^{7}$

Para a análise realizou-se uma leitura minuciosa das entrevistas transcritas e impressas, onde cada entrevista foi analisada individualmente e, na medida em que os temas foram emergindo, os mesmos foram marcados através de cores. Após essa etapa, criou-se um varal onde as entrevistas foram fixadas e expostas para facilitar a análise cromática dos temas, para iniciar a exploração do material e interpretação dos resultados.

A pesquisa respeitou a Resolução do Conselho Nacional de Saúde $n^{\circ} 466$, de 12 de dezembro de 2012, e foi avaliada por Comitê de Ética em Pesquisa com Seres Humanos, sendo aprovada com Certificado de Apresentação para Apreciação Ética $\mathrm{n}^{\circ}$ 162266613.8.0000.5346. Todos os participantes assinaram o Termo de Consentimento Livre e Esclarecido. 


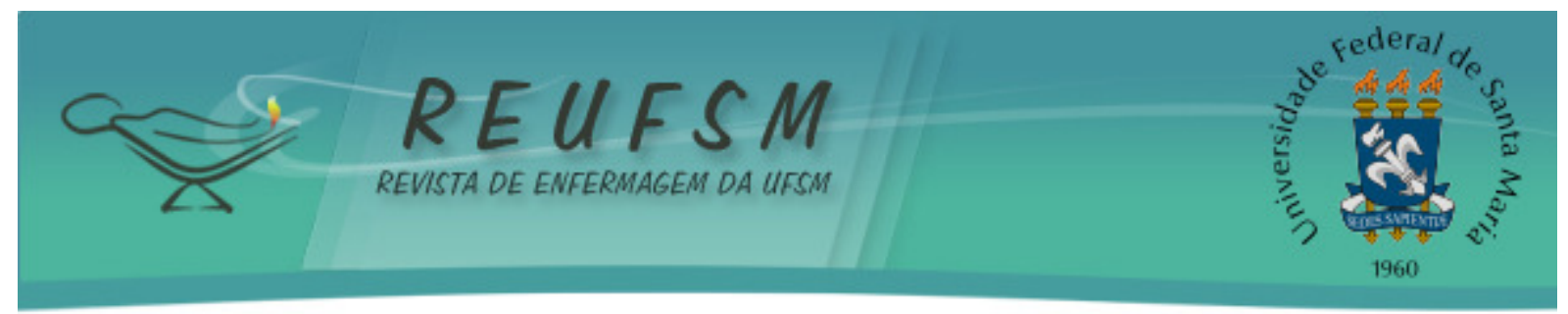

\section{RESULTADOS E DISCUSSÃO}

Os participantes da pesquisa tinham entre 33 e 53 anos de idade, e a maioria era do sexo feminino (80\%). O tempo de serviço na unidade variou entre 10 e 25 anos. Dois possuíam outro emprego e a carga horária de trabalho semanal era, em média, de 30 horas. Todos os participantes eram especialistas, um estava cursando mestrado e outro, doutorado. Desses, três possuíam qualificação na área de gestão.

\section{Facilidades da gestão na qualidade em unidade de clínica cirúrgica}

Para compor esta categoria, identificou-se, por meio dos relatos dos entrevistados, que a experiência profissional, a interação com a equipe e a integração com o ambiente de trabalho são os temas identificados como facilitadores no desenvolvimento da gestão da qualidade na assistência em unidade de clínica cirúrgica.

0 desenvolvimento de uma gestão de qualidade na assistência de enfermagem tem sido um desafio para as equipes, uma vez que há vários aspectos a serem observados de maneira cuidadosa. As peculiaridades que envolvem essa assistência ao paciente cirúrgico requerem profissionais que estejam preparados para atender as mais diversas situações presentes no período perioperatório.

Nesse contexto, a qualidade na assistência ao paciente é revelada não somente por meio de um atendimento individualizado, mas na capacidade de oferecer um tratamento integral de acordo com suas necessidades, com resultados eficazes e satisfatórios. ${ }^{8}$ Entende-se que a busca constante pela excelência nos serviços de saúde é pautada na integralidade das ações direcionadas aos pacientes, conforme mostra o relato a seguir:

[...] a gente tem autonomia por estar mais tempo no serviço. A gente consegue intervir sobre certas condutas médicas, por exemplo, uma alta [...], uma ferida, ou o paciente precisa ter um familiar que não veio, para orientarmos sobre cuidados. (E1)

Percebe-se, assim, que a experiência adquirida ao longo da atividade profissional mostra-se como adicional que proporciona habilidades que podem ser transformadas em aliados no trabalho, como a autonomia e o respeito profissional, trazendo resultados positivos para recuperação dos pacientes.

A autonomia profissional em enfermagem pode ser definida como a capacidade do enfermeiro em cumprir suas funções profissionais de maneira autodeterminada, cumprindo, ao mesmo tempo, os aspetos legais, éticos e práticos da profissão. ${ }^{9}$

[...] o relacionamento interpessoal acho fundamental, porque, no momento que tu não tens parceiros, tu não consegues avançar nas tuas decisões, no que pretendes fazer. (E2)

Estar integrado ao ambiente onde se trabalha constitui um fator relevante para o desenvolvimento do trabalho assistencial, assim como as relações no ambiente de trabalho. Dessa forma, as relações interpessoais são fortemente vistas como um potencializador na busca por resultados, pois a assistência na enfermagem com qualidade pode ser mais facilmente alcançada se houver união entre as equipes que compõem os serviços de saúde.

Este resultado encontrado, de que a manutenção de um bom relacionamento interpessoal facilita a gestão do cuidado, também foi um dos achados de uma pesquisa que 


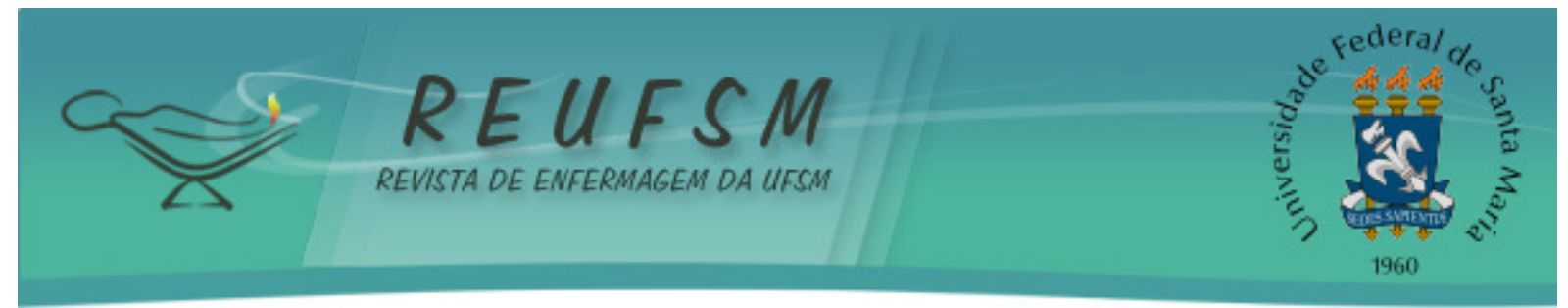

avaliou os aspectos que facilitam o gerenciamento de enfermagem em unidade coronariana. $^{10}$

É imprescindível articular as diversas ações realizadas no interior de um setor, unidade ou serviço, além de integrar os profissionais dos setores, unidades e serviços entre si, visto que devem ser consideradas as múltiplas dimensões das necessidades de saúde. ${ }^{11}$ Isso pode ser visto no relato a seguir:

[...] precisa ter um bom relacionamento com o pessoal que trabalha aqui, toda a equipe, tanto de enfermagem quanto de manutenção, limpeza. (E3)

[...] se tem uma intercorrência e precisa de residente da clínica, tem que interagir com ele, vamos combinando $e$ assistindo ao paciente. (E4)

Entende-se que a familiarização com os diversos cenários que compõem o trabalho na enfermagem pode ser considerada como uma ferramenta que auxilia na busca pela assistência integral, bem como a dedicação e o envolvimento de todos os servidores que complementam um ambiente harmonioso de trabalho, refletindo, diretamente, na qualidade da assistência. A compreensão das relações interpessoais é fundamental para o cuidado em saúde, uma vez que os profissionais utilizam-se destas ferramentas para alcançar o cuidado efetivo. ${ }^{12}$

$\mathrm{Na}$ saúde, os profissionais desempenham papéis de extrema relevância, executando atividades essenciais para o bom desenvolvimento do serviço, aprimorando técnicas e procedimentos que levam a instituição a atingir seus objetivos e a melhorar a qualidade do serviço, tornando o trabalho mais prazeroso. ${ }^{8}$

[...] quanto às facilidades é exatamente isso: termos profissionais que são corretos, dedicados e têm conhecimento. (E5)

Entende-se, assim, que a enfermagem se caracteriza pela busca constante do aprimoramento de conhecimentos, visto que é uma profissão que atua com pessoas que se encontram, na maioria das vezes, fragilizadas.

Percebeu-se que a experiência profissional é apontada como uma facilidade na gestão da qualidade na assistência de enfermagem, conferindo autonomia aos profissionais e auxiliando no desenvolvimento de habilidades necessárias para o cotidiano de trabalho. A experiência é relevante no desenvolvimento das ações assistenciais voltadas para a qualidade da assistência, pois é um facilitador no cotidiano do trabalho. Os trabalhadores que compõem as frentes de trabalho na saúde devem atender às demandas apresentadas pelos pacientes, tornando-se necessário que os profissionais reconheçam as conexões que existem entre as diversas atividades executadas e articulem suas ações com os demais componentes da equipe. ${ }^{11}$

[...] o que me facilitou foi o amadurecimento com o tempo, a experiência e a busca [...] eu acho que o tempo, as leituras que a gente faz, as trocas com os colegas, os cursos, tudo isso ajuda a gente a desenvolver e ampliar certas habilidades que a gente precisa ter para desenvolver essa assistência de maneira mais fácil. (E10) 


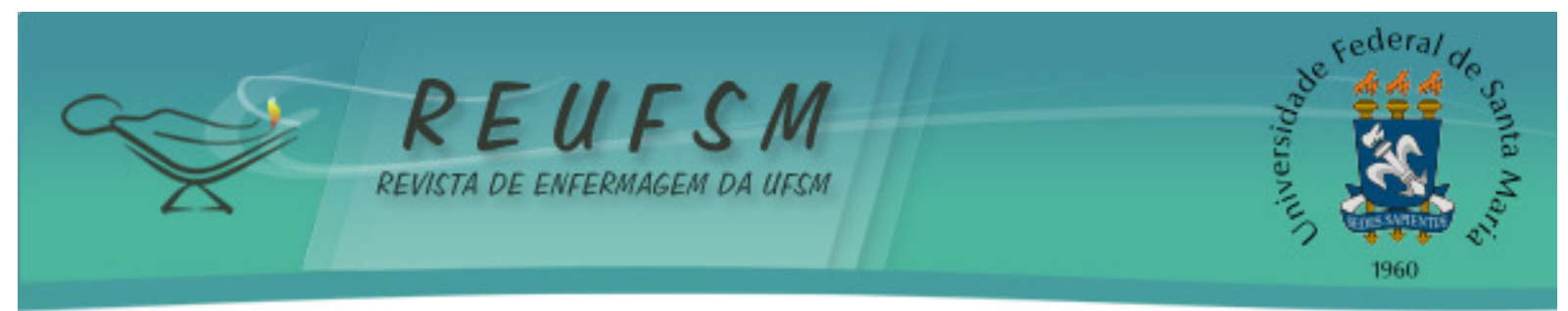

Compreendendo-se a complexidade dos sistemas de saúde e a diversidade de novos produtos, medicamentos e equipamentos que estão disponíveis hoje no mercado, devem ser consideradas as questões relativas às escolhas e decisões sobre as novas tecnologias que devem ser incorporadas. ${ }^{13}$ A busca pelo melhor para o paciente é uma constante nos discursos, isto pode ser visto no relato a seguir.

[...] a gente testa os materiais, consegue materiais de qualidade, a parte de curativos de cobertura, a gente consegue ter, uma conversa com a padronização. (E1)

Nesse sentido, quando a enfermagem seleciona os recursos a serem utilizados, ela pensa no bem-estar e no que é melhor para o paciente, ou seja, ela busca o melhor material, ou o melhor procedimento.

A troca de informações e o compartilhamento de saberes proporcionam o desenvolvimento das ações assistenciais, uma vez que essa relação enriquece o conhecimento dos trabalhadores. Observa-se, então, que os enfermeiros citaram as facilidades como um aprimoramento do cuidado e que as mesmas contribuem para uma assistência de qualidade.

\section{Dificuldades da gestão na qualidade em unidade de clínica cirúrgica}

Ao mesmo tempo em que se vivenciam fatores que facilitam o cotidiano do trabalho na enfermagem, encontram-se situações que dificultam o desenvolvimento de suas ações. Assim, torna-se evidente a necessidade de identificá-las, visando à busca da qualidade na assistência.

Esta categoria emergiu a partir dos temas revelados nas entrevistas, que se direcionaram para a sobrecarga de trabalho, o número insuficiente de profissionais de enfermagem, a carência da estrutura física e a insuficiência de recursos materiais.

A enfermagem, na sua formação, é direcionada para a integralidade das ações assistenciais, no entanto, existe a necessidade de adequação das instituições hospitalares quanto ao quantitativo de profissionais, especialmente de enfermeiros. ${ }^{14}$

[...] não tem pessoal suficiente para atender a demanda [...] o paciente pós-operatório necessita de mais cuidado que um paciente pré-operatório, que está caminhando e realizando suas atividades da vida diária [...] ficar com o cuidado que demanda mais faz com que essas pessoas fiquem sobrecarregadas. (E2)

Aqui na unidade temos cuidados bem específicos, preparo para cirurgias, curativos grandes. [...] Há sobrecarga de trabalho e a gente fica com 46 pacientes. É um enfermeiro só à noite. (E9)

Temos uma das maiores unidades do hospital. São pacientes graves, que vêm de cirurgias grandes e exigem mais atenção. $O$ paciente pode desestabilizar, se for pensar na qualidade do cuidado, tem um número elevado de pacientes graves. (E10)

Uma das maiores dificuldades encontradas pela equipe de enfermagem nas instituições hospitalares é referente à insuficiência de profissionais em relação à demanda de atendimento cada vez mais complexa dos pacientes. ${ }^{15}$ 


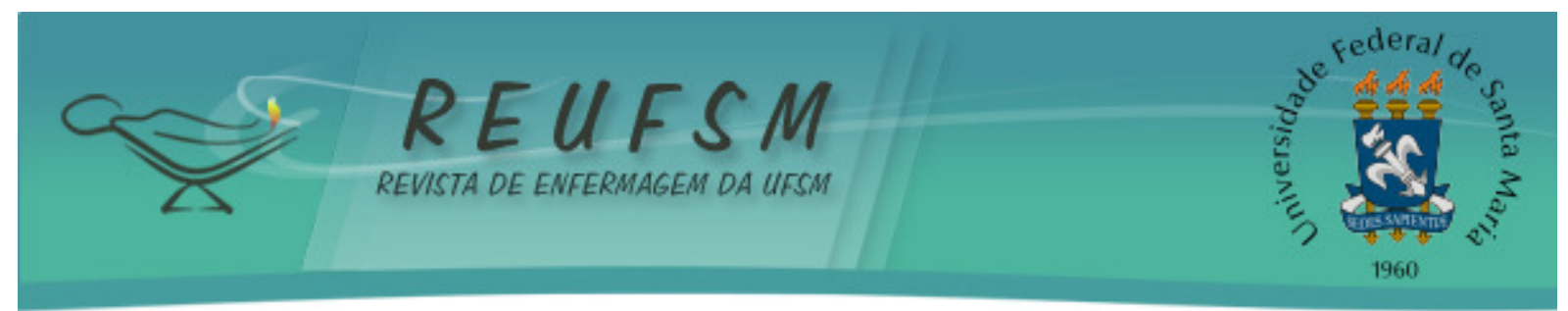

Conhecer e avaliar a realidade pode auxiliar o enfermeiro a elaborar propostas, tomar decisões e negociar a readequação do quadro de pessoal e dos processos de trabalho. No entanto, ainda é um grande desafio para os gerentes de enfermagem o equilíbrio entre a utilização de recursos humanos e qualidade da assistência. ${ }^{16}$

\section{[...] precisamos de um quantitativo mínimo para atender essa} demanda [...] há falta, há carência de recursos humanos. (E2)

Não digo que a nossa equipe não é qualificada, [...] mas é que essa falta de funcionários acaba sobrecarregando a equipe que está aqui [...] (E6)

O enfermeiro, como gerenciador do cuidado, é responsável por prover uma escala mínima de trabalhadores para atender a demanda e a complexidade de trabalho. Mas, por vezes, isso não é possível devido à escassez de profissionais na instituição, o que acaba refletindo na qualidade da assistência prestada.

Estudo realizado num hospital público demonstra carência de profissionais, tornando evidente esta problemática associada à sobrecarga de trabalho dos profissionais de enfermagem, comprometendo a qualidade da assistência e a segurança do paciente e dos profissionais. ${ }^{17}$

Instituições de saúde mantêm, por questões financeiras, número reduzido de enfermeiros, comprometendo a manutenção de assistência com qualidade e a supervisão do serviço. Essa situação coloca em risco a segurança do paciente, uma vez que atividades exclusivas do enfermeiro são delegadas aos profissionais de nível técnico, com implicações ético-legais para o enfermeiro e para a instituição. ${ }^{16}$

0 número insuficiente de profissionais de enfermagem pode contribuir para elevar o índice de absenteísmo, como consequência da sobrecarga e insatisfação dos trabalhadores. ${ }^{18}$

Se não fosse o elevado número de atestados na unidade, daria para manter uma escala maior. Tem meses que tu consegue fechar a escala [...] mas não tem um mês que não tenha alguém de atestado, que daí tu acaba sobrecarregando aqueles que ficam [...] (E6)

Temos uma previsão de enfermeiros, técnicos, mas existem situações em que a pessoa fica doente, não vem trabalhar. (E10)

Em estudo realizado com os profissionais de enfermagem num hospital universitário, a unidade de atendimento que registrou as maiores taxas de absenteísmo foi a Clínica Cirúrgica. ${ }^{19}$ Entende-se que 0 absenteísmo representa transtornos para a organização do trabalho e para a assistência prestada ao paciente, além de provocar uma sobrecarga de trabalho para os demais profissionais, levando ao adoecimento dos trabalhadores. ${ }^{20}$

Nesse contexto, destaca-se que a ausência de uma equipe mínima dificulta o trabalho, uma vez que cada profissional tem funções específicas que contribuem para o cuidado. Além disso, os participantes da pesquisa apontaram a possibilidade de falta de comprometimento por parte dos profissionais com seu trabalho, que pode ser identificada como uma dificuldade da gestão da qualidade.

Dificuldade é a [...] falta de comprometimento, a garantia da estabilidade [...]. (E4) 


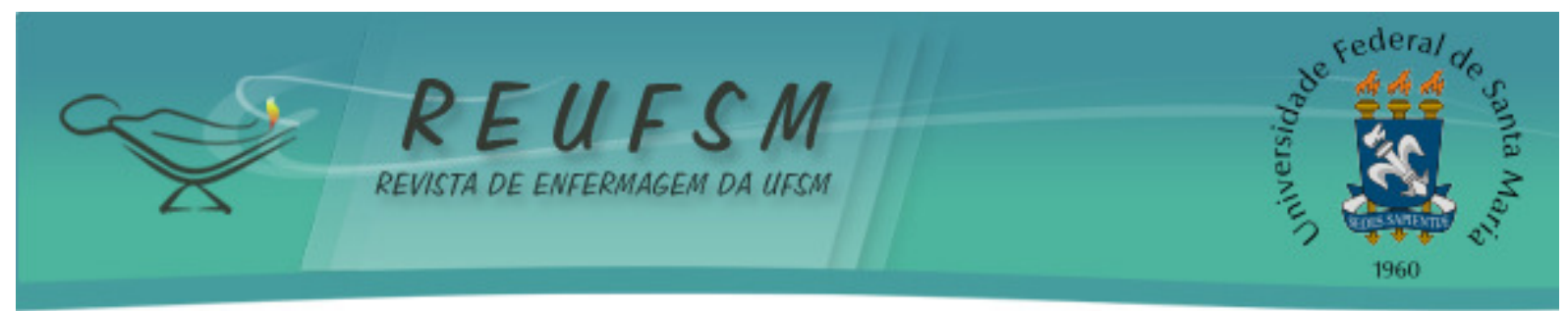

Estudo revela que o comprometimento profissional é de fundamental importância no processo de atendimento, gerando melhores resultados junto aos pacientes. ${ }^{21}$ No entanto, a escolha do ambiente de trabalho, conferida por meio de concursos públicos, tem sido uma forma buscada pela maioria dos profissionais na atualidade, visto que o regime jurídico de trabalho - estatutário - confere certa estabilidade ao servidor. Entretanto, alguns enfermeiros relataram a necessidade de intervir no modo como é realizada esta seleção, conforme apontado nas entrevistas a seguir.

[...] a seleção é só prova objetiva, teria que ter uma avaliação psicológica [...] para trabalhar dentro de um hospital, ainda mais no nosso de alta complexidade, tem pessoas que não tem perfil nenhum. (E4)

Falta talvez uma seleção melhor [...] tem profissionais que [...] poderiam ser remanejados para outros setores [...] (E5)

0 enfermeiro deve apresentar competências como requisito básico para o enfrentamento do mercado de trabalho, e para desenvolver padrões de excelência bem como melhores resultados organizacionais. A falta de conhecimento e experiência é vista como um fator que prejudica o desempenho profissional. ${ }^{22}$

Dessa forma, é indispensável que as instituições tenham como objetivo capacitar seus profissionais, tendo em vista o crescimento do nível de informação e inovações tecnológicas. ${ }^{22}$

Falta aquela coisa de incentivar mais, de fazer mais capacitações [...]. (E6)

Falta o treinamento periódico dos funcionários. (E8)

Os participantes da pesquisa apontaram que sentiam a necessidade de participar de mais atividades de educação continuada, além de receber mais incentivo por parte da instituição para tal atividade.

Ainda, dentre as dificuldades para a gestão da qualidade em unidade de clínica cirúrgica, direciona-se o olhar para a estrutura física, equipamentos de trabalho e materiais, que interferem na qualidade da assistência.

[...] tem bastante medicação que no momento o hospital não dispõe, termina certa medicação, e tem que correr atrás do médico para ele alterar a prescrição [...]. (E1)

[...] dá um transtorno danado para nós [...] ter um elevador em que não cabem as camas [...] é uma questão estrutural, mas é uma questão de gestão também [...]. (E3)

Quando tem material, tem de sobra, tu pode usar bastante. Mas quando falta, falta mesmo, tu não tem, muitas vezes, falta material para curativo, coberturas. (E6)

Estudo evidenciou a centralização na tomada de decisão do profissional responsável pela compra, que, por vezes, desconhece as especificações de alguns materiais, interferindo na escolha de produtos específicos para determinados setores. No 


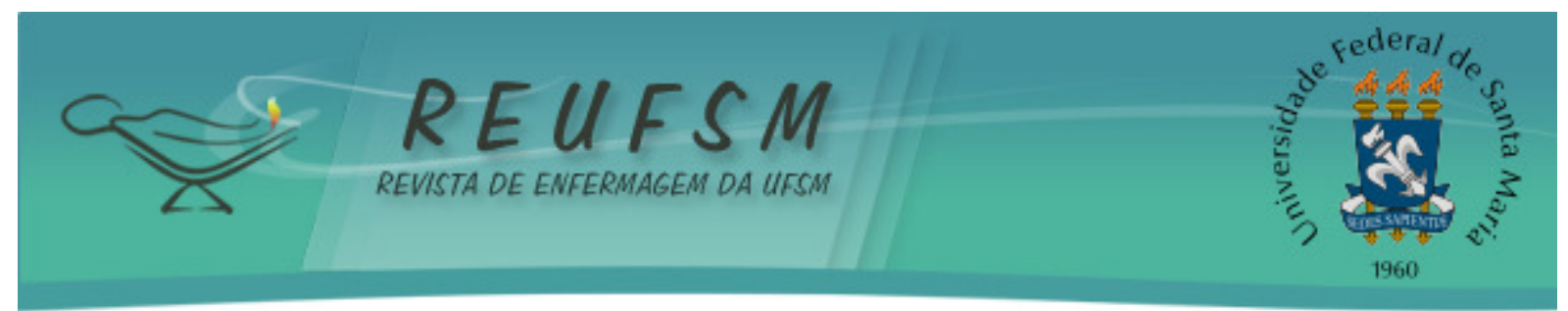

entanto, a participação do enfermeiro tem se tornado notável, melhorando a qualidade e a quantidade dos produtos. ${ }^{23}$

Pesquisa mostrou que a disponibilidade de equipamentos confere suporte ao atendimento e qualifica a assistência; já sua falta compromete a qualidade do serviço ofertado, impossibilita a execução de ações de forma resolutiva e desgasta o profissional, pela constante cobrança de respostas às solicitações de manutenção e reposição. ${ }^{24}$

Além da disponibilidade de materiais em quantidade adequada, é indispensável que este tenha qualidade para atender as necessidades do paciente e serviços. As especificações dos materiais padronizados e não padronizados possibilitam a obtenção de materiais de qualidade. ${ }^{23}$

[...] às vezes é uma capacitação para fazer sobre higienização das mãos e tu não tens uma pia adequada, a torneira adequada para que isso ocorra no teu dia a dia. (E1)

[...] nós não temos monitor para uma situação de parada, estão muito velhos, muito estragados, e você não consegue monitores com os outros andares porque estão com o mesmo problema que nós [...]. (E7)

Estudo mostrou que alguns dos problemas enfrentados são o mau uso dos equipamentos e a falta de manutenção, sendo lento o processo de manutenção corretiva e ausente o de manutenção preventiva. ${ }^{23}$

A avaliação do paciente depende não só do enfermeiro e de seus conhecimentos, mas necessita de tecnologias que facilitem a assistência prestada ao paciente. Neste aspecto, destaca-se, também, a implementação de sistemas informatizados na saúde.

Esses recursos são capazes de propagar de maneira rápida, fácil e segura as informações indispensáveis para auxiliar os profissionais no processo de trabalho, possibilitando o planejamento e a organização de suas ações. ${ }^{25}$

[...] o hospital não dispõe de recursos, a própria informatização, então a gente acaba levando muito tempo para fazer o aprazamento dos [...] leitos, seja farmácia, que daí não vem a medicação, tem que ir atrás [...] então você acaba se sobrecarregando [...]. (E1)

Os serviços de saúde apresentam uma complexidade variada que vai ao encontro do tamanho e da estrutura da instituição, envolvendo o número de funcionários, tamanho da equipe multiprofissional e recursos materiais para atender os pacientes, conforme suas necessidades e gravidade da doença. ${ }^{8}$

Ainda, apesar das adversidades vivenciadas pelos entrevistados, os mesmos revelaram que a participação dos gestores deve apresentar uma relação estreita com seus gerenciados, para a obtenção de êxito na busca pela qualidade. Assim, as dificuldades no desenvolvimento da gestão de qualidade em unidade de clínica cirúrgica devem ser observadas e corrigidas em curto espaço de tempo, a fim de não prejudicar a qualidade da assistência. Nota-se que os enfermeiros conheciam suas dificuldades e sugeriram soluções para as mesmas, no entanto, o processo de mudança não depende somente da enfermagem, e sim do contexto organizacional. 


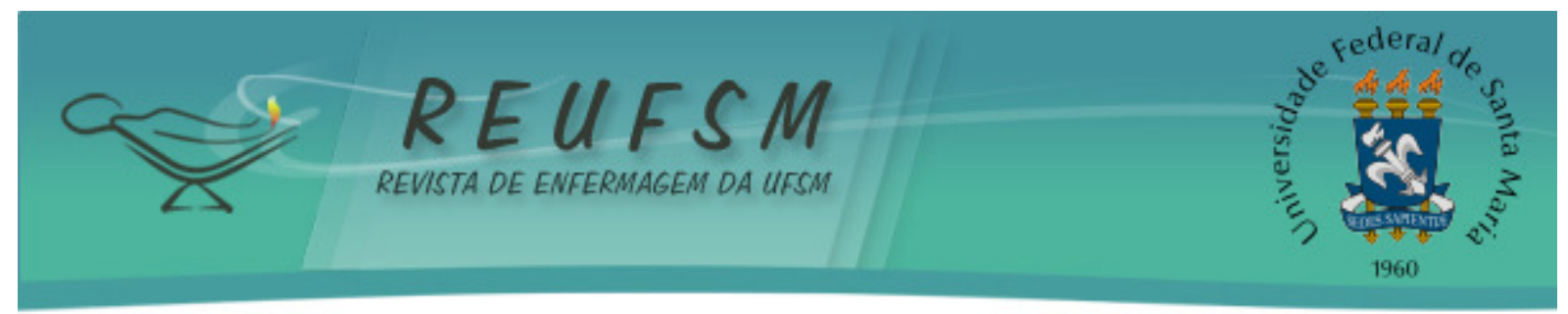

\section{CONSIDERAÇÕES FINAIS}

Com este trabalho foi possível conhecer a as facilidades e as dificuldades na gestão da qualidade na assistência de enfermagem em unidade de clínica cirúrgica. Como facilidades, foram apontadas a experiência profissional, a interação com a equipe e a integração com o ambiente. Como dificuldades, foram identificadas a sobrecarga de trabalho, o número insuficiente de profissionais de enfermagem, a estrutura física e insuficiência de recursos materiais.

Diante da relevância da gestão do cuidado como estratégia para a efetivação de uma assistência hospitalar de qualidade, este estudo poderá contribuir na medida em que auxilia na identificação dos fatores que facilitam e dificultam a gestão na qualidade da assistência em enfermagem. A partir da identificação destes fatores, as gerências de enfermagem podem, como chefes de equipe, buscar formas de melhorá-la. Como estratégias para superar as dificuldades na gestão da qualidade, sugere-se a realização de dimensionamento do pessoal de enfermagem, adequação da estrutura física, previsão e provisão de recursos materiais.

Sugere-se que novos estudos sejam realizados, a fim de evidenciar em outros contextos a percepção das facilidades e dificuldades na gestão da qualidade na assistência de enfermagem para a busca de um cuidado efetivo e de excelência na saúde.

\section{REFERÊNCIAS}

1. Bonato VL. Gestão da qualidade em saúde: melhorando assistência ao cliente. Mundo Saúde [Internet]. 2011 [acesso em 2014 out 15];35(5):319-31. Disponível em: http://www.saocamilo-sp.br/pdf/mundo_saude/86/319a331.pdf.

2. Donabedian A. Evalución de la calidad de la atención médica. In: White KL, Frank J, Ordoñez C, Paganini JM, Starfield B, organizadores. Investigaciones sobre serviçios de salud: una antologia. Washington: OPAS; 1992. p. 382-404.

3. Donabedian A. The role of outcomes in quality assessment and assurance. QRB Qual Rev Bull. 1992 Nov, 18(11):356-60.

4. Rocha ESB, Trevizan MA. Gerenciamento da qualidade em um serviço de enfermagem hospitalar. Rev Latinoam Enferm [Internet]. 2009 [acesso em 2014 out 15];17(2):35-44. Disponível em: http://www.redalyc.org/pdf/2814/281421907016.pdf.

5. Silva RC, Ferreira MA. A tecnologia em saúde: uma perspectiva psicossociológica aplicada ao cuidado de enfermagem. Esc Anna Nery Rev Enferm [Internet]. 2009 [acesso em];13(1):169-73. Disponível em: http://www.revistaenfermagem.eean.edu.br/detalhe_artigo.asp?id=412.

6. Hospital Universitário de Santa Maria (HUSM). Apresentação [Internet]. [acesso em 2014 set 29]. Disponível em: http: / /www.husm.ufsm.br/index.php?janela=historico.html.

7. Minayo MCS. O desafio do conhecimento: pesquisa qualitativa em saúde. $13^{\mathrm{a}}$ ed. São Paulo: Hucitec; 2013.

8. Luongo J, organizadora. Gestão da qualidade em saúde. São Paulo: Ridell; 2011.

9. Ribeiro JMS. Autonomia profissional dos enfermeiros. Rev Enferm Referência [Internet]. 2011 [acesso em 2014 out 15];III(5):27-36. Disponível em:

http://www.scielo.mec.pt/pdf/ref/vserllln5/serllln5a03.pdf.

10. Aguiar DF, Conceição-Stipp MA, Leite JL, Mattos VZ, Andrade KBS. Gerenciamento de enfermagem: situações que facilitam ou dificultam o cuidado na unidade coronariana. Aquichan 


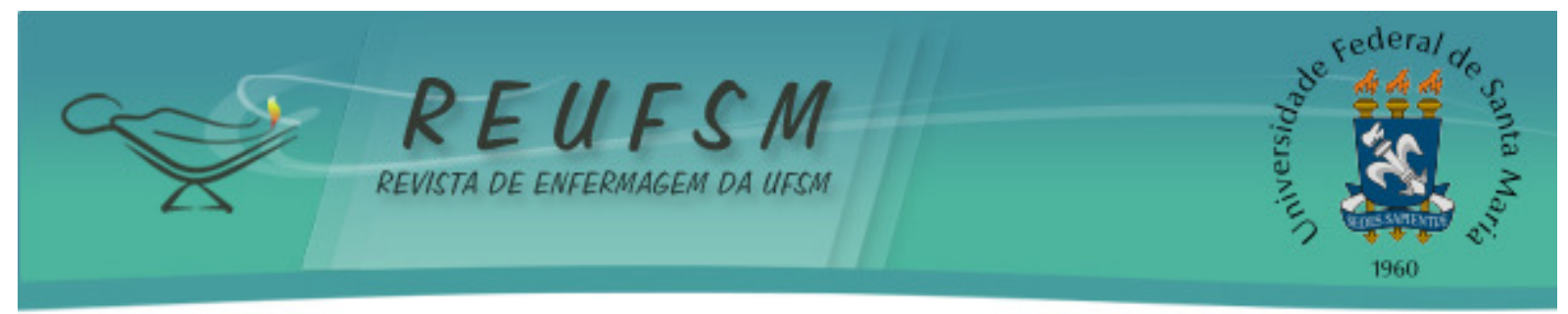

[Internet]. 2010 [acesso em 2014 out 15];10(2):115-31. Disponível em:

http: //aquichan.unisabana.edu.co/index.php/aquichan/article/view/1679/2171.

11. Peduzzi M, Ciampone MHT. Trabalho em equipe e processo grupal. In: Kurcgant P. coordenadora. Gerenciamento em enfermagem. $2^{\mathrm{a}}$ ed. Rio de Janeiro (RJ): Guanabara Koogan; 2010. p. 105-20.

12. Formozo GA, Oliveira DC, Costa TL, Gomes AMT. As relações interpessoais no cuidado em saúde: uma aproximação ao problema. Rev Enferm UERJ [Internet]. 2012 [acesso em 2014 out 15];20(1):124-7. Disponível em: http://www.facenf.uerj.br/v20n1/v20n1a21.pdf.

13. Brasil. Ministério da Saúde. Secretaria da Ciência, Tecnologia e insumos estratégicos. Departamento de Cência e Tecnologia. Política nacional de gestão de tecnologias em saúde versão preliminar. Brasília (DF): MS; 2007. 50 p.

14. Menegueti MG, Nicolussi AC, Scarparo AF, Campos LF, Chaves LDP, Laus AM. Dimensionamento de pessoal de enfermagem nos serviços hospitalares: revisão integrativa da literatura. Rev Eletrônica Enferm [Internet]. 2013 [acesso em 2014 out 15];15(2):551-63. Disponível em: http://www.fen.ufg.br/revista/v15/n2/pdf/v15n2a30.pdf.

15. Souza GPS, Freitas GF, Prado C, Leite MMJ, Pereira IM. A problemática da elaboração da escala mensal de enfermagem. Acta Paul Enferm [Internet]. 2011 [acesso em 2014 out 15];24(1):137-41. Disponível em: http://www.scielo.br/pdf/ape/v24n1/v24n1a21.pdf.

16. Cucolo DF, Perroca MG. Reestruturação do quadro de pessoal de enfermagem e seu impacto sobre as horas de assistência. Rev Latinoam Enferm [Internet]. 2010 [acesso em 2014 out 15];18(2):1-9. Disponível em: http://www.scielo.br/pdf/rlae/v18n2/pt_06.

17. Barbosa HB, Paiano LAG, Nicola AL, Fernandes LM. Nível de complexidade assistencial de pacientes e o quantitativo de profissionais de enfermagem. Rev Enferm UFSM [Internet]. 2014 [acesso em 2014 out 15];4(1):29-37. Disponível em: http://cascavel.ufsm.br/revistas/ojs2.2.2/index.php/reufsm/article/view/9230/pdf.

18. Fugulin FMT, Gaidzinski RR, Kurcgant P. Ausências previstas e não previstas da equipe de enfermagem das unidades de internação do HU-USP. Rev Esc Enferm USP [Internet]. 2003 [acesso em 2014 out 15];37(4):109-17. Disponível em: http://www.revistas.usp.br/reeusp/article/viewFile/41373/44948.

19. Sancinetti TR, Soares AVN, Lima AFC, Santos NC, Melleiro MM, Fugulin FMT, et al. Taxa de absenteísmo da equipe de enfermagem como indicador de gestão de pessoas. Rev Esc Enferm USP [Internet]. 2011 [acesso em 2014 out 15];45(4):1007-12. Disponível em: www.revistas.usp.br/reeusp/article/download/40797/44159.

20. Umann J, Guido LA, Leal KP, Freitas EO. Absenteísmo na equipe de enfermagem no contexto hospitalar. Cienc Cuid Saúde [Internet]. 2011 [acesso em 2014 out 15];10(1):184-90. Disponível em: http://periodicos.uem.br/ojs/index.php/CiencCuidSaude/article/do wnload/11867/pdf.

21. Andrade LM, Martins EC, Caetano JA, Soares E, Beserra EP. Atendimento humanizado nos serviços de emergência hospitalar na percepção do acompanhante. Rev Eletrônica Enferm [Internet]. 2009 [acesso em 2014 out 15];11(1):151-7. Disponível em: http: //www.fen.ufg.br/revista/v11/n1/pdf/v11n1a19.pdf.

22. Ferreira JCOA, Kurcgant P. Capacitação profissional do enfermeiro de um complexo hospitalar de ensino na visão de seus gestores. Acta Paul Enferm [Internet]. 2009 [acesso em 2014 out 15];22(1):31-6. Disponível em: http://www.scielo.br/pdf/ape/v22n1/a05v22n1. 


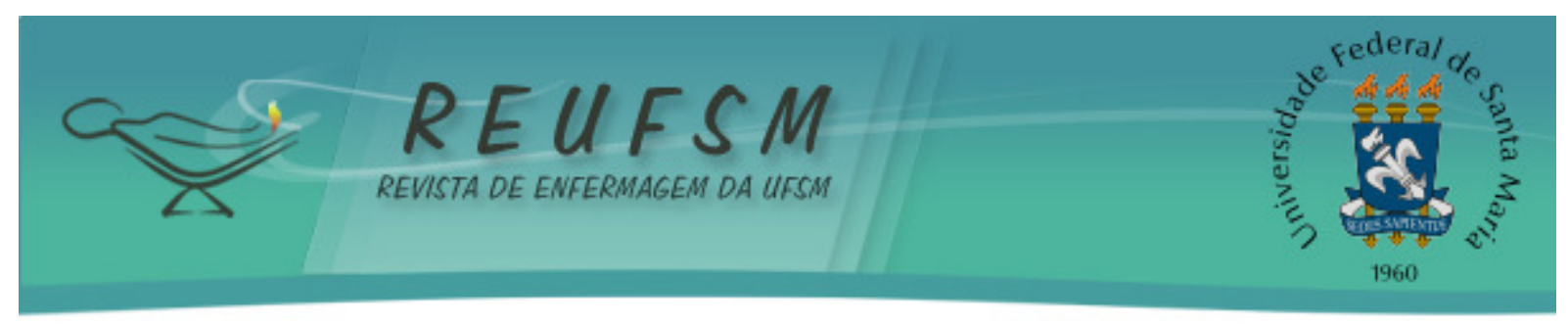

23. Garcia SD, Haddad MCL, Dellaroza MSG, Costa DB, Miranda JM. Gestão de material médico-hospitalar e o processo de trabalho em um hospital público. Rev Bras Enferm [Internet]. 2012 [acesso em 2014 out 15];65(2):339-46. Disponível em: http://www.scielo.br/pdf/reben/v65n2/v65n2a21.pdf.

24. Pedrosa ICF, Corrêa ACP, Mandú ENT. Influências da infraestrutura de centros de saúde nas práticas profissionais: percepções de enfermeiros. Cienc Cuid Saúde [Internet]. 2011 [acesso em 2014 out 15];10(1):58-65. Disponível em:

http://www.periodicos.uem.br/ojs/index.php/CiencCuidSaude/article/view/13288/pdf.

25. Benito GAV, Licheski AP. Sistemas de informação apoiando a gestão do trabalho em saúde. Rev Bras Enferm [Internet]. 2009 [acesso em 2014 out 15];62(3):447-50. Disponível em: http://www.scielo.br/pdf/reben/v62n3/18.pdf.

Data de recebimento: $14 / 10 / 2014$

Data de aceite: 17/04/2015

Contato do autor responsável: Liange Arrua Rabenschlag

Endereço postal: Rua Felipe de Oliveira n 155 apto. 101, Bairro Medianeira, Santa Maria, Rio Grande do Sul, Brasil. CEP 97015-250.

E-mail: licaufsm@hotmail.com 